\title{
Uma Conversa sobre Arqueologia, Paisagem e Percepção com Robin o Bom Camarada
}

\author{
José Roberto Pellini*
}

PELLINI, J.R. Uma Conversa sobre Arqueologia e Paisagem com Robin o Bom Camarada. Revista do Museu de Arqueologia e Etnologia, São Paulo, 19: 21-37, 2009.

Resumo: O que é Paisagem? Como se define a relação entre homem e natureza? Quais os símbolos e significados por detrás da Paisagem? Seriam as abordagens exclusivamente centradas nas reconstruções paleoambientais as mais próximas da realidade? É a paisagem emocional de James Pryde e William Blake, a paisagem realista de Delacroix e Velázquez, a liberdade e energia de Van Gogh e Bomberg, as memórias e sonhos de Dali, Chagall e Carel Weight menos verdadeiras que as reconstruções paleoambientais propostas pela ciência arqueológica? Segundo o ensaísta suíço do século 19 Henry Frederic Amiel o que difere estas paisagens é apenas a mente. Eu diria que não apenas a mente, mas a percepção que os indivíduos têm de seu mundo.

Palavras-chave: Fenomenologia - Percepção - Arqueologia - Paisagem.

A s crianças de domingo enxergam jardins mágicos onde não há nada para as outras pessoas; elas encontram tesouros onde outros passam sem prestar atenção...... A única explicação possível para esses fenômenos é que as crianças de domingo teriam uma percepção diferente, mais feliz que as pessoas comuns, sem que uma das duas fosse equivocada, nem verdadeira. A percepção não é atingida por essa alternativa. (Benjamin 1991: 66-67)

\section{Ato I: Sonhos de uma noite de Verão}

Entra Puck: Ah como é difícil se debruçar diretamente na frente de um computador e

(*) Pontifícia Universidade Católica de Goiás -PUCGO. jrpellini@yahoo.com.br escrever, mesmo porque se formos nos debruçar sobre ele provavelmente não iremos escrever. Eu ainda prefiro o papel e a caneta, pode ser pouco ecológico já que perco mil páginas de tantos rabiscos e folhas amassadas, mas gosto de como o contato direto com o papel e a caneta; me faz mais próximo do tema, criando uma sensação de intimidade, a mesma intimidade do escultor que vai trabalhando cada textura cada veio da madeira quando esculpe. Mas mesmo na quietude da madrugada ainda é difícil escrever. Creio que o motivo seja o fato de que em geral somos impedidos tanto pela sociedade quanto pela ciência, a fantasiar. Me pergunto porque não nos permitimos uma maior liberdade interpretativa ao lidarmos com o passado? Porque não podemos criar um mundo habitado por fadas e duendes, onde Puck e Oberon convivem com sininho e 
Capitão Gancho, quando deparamos com um novo sitio arqueológico? Porque não podemos avançar nas brumas e nos permitir um salto imaginativo? Porque é infantil diriam os adultos. Porque não são reais diria minha terapeuta. Porque tira a credibilidade diria a sociedade científica. Porque não imaginar a roda em volta da fogueira e Helena quebrando um pote cerâmico e jogando os refugos ao lado da brasa acesa? Porque não há provas diriam os arqueólogos. Mas quais são essas provas tão irrefutáveis da ciência arqueológica que impedem o sonho, a fantasia e a imaginação? O que há de real na realidade, o que há de real nos cacos, o que há de real na paisagem?

Talvez seja a falta da imaginação, de paixão, de imersão, que tanto desumanize a paisagem quando esta é tratada em textos de arqueologia. Concordo com Tilley (2004), que quase toda a literatura que trata direta ou indiretamente da paisagem parece desencorpada, fria e estática. O que difere a Paisagem retratada por Cézanne, da Paisagem de descrita por Kossinna, ou a Terra do Nunca imaginada por Barrie, ${ }^{1}$ da Paisagem descrita por Tilley ou por Milton Santos?.2 Segundo o ensaísta suíço do século 19 Henry Frederic Amiel o que difere estas paisagens é apenas a mente. Eu diria que não apenas a mente, mas os indivíduos. "A primavera, o verão, o fértil outono, o cru inverno mudam suas faces habituais; e o mundo assombrado não sabe distingui-lo por seus produtos. O que engendra esses males são nossos debates e nossas dissensões." ${ }^{3}$ Será que não compreendemos o mundo porque preferimos defini-lo a percebê-lo? Será por isso que temos a eterna sensação de que algo nos escapa quando pretendemos discutir e representar uma paisagem? Será que isso que nos escapa, nos escapa porque estamos ainda presos a discussões intermináveis? Quando será que o mundo perdeu suas cores e sua poesia? Alguns

(1) Sir James Matthew Barrie.

(2) Christopher Tilley (arqueólogo). Milton Santos (geógrafo brasileiro).

(3) Shakespeare, W. 2005. Sonhos de Uma Noite de Verão. São Paulo. Martin Claret. diriam que foi quando a ciência resolveu dividir a Paisagem em diferentes gavetas na estante do boticário. Mas como juntar os fragmentos?

\section{Ato II: A percepção}

Quando tentamos descrever um arbusto verdejante ou um perfil estratigráfico em campo o que estamos realmente fazendo? Será que aquele arbusto é um arbusto, será que o verde exuberante é um verde exuberante? $\mathrm{O}$ quão subjetiva pode ser a realidade que nos cerca? Será que nossas descrições representam a realidade? Os empiristas diriam que sim e os idealistas diriam que não.

Para os empiristas a realidade é material, física e possui características que são intrínsecas a ela e que independem do sujeito. Sendo assim nosso perfil estratigráfico deveria apresentar as mesmas formas, texturas, cores e intrusões independentemente de quem o estivesse observando. Caberia ao sujeito captar as informações na forma de sensação e organizálas na forma de percepção. O conhecimento seria assim a associação das sensações na percepção. A sensação seria a recepção dos impulsos sensoriais e a percepção seria a organização e codificação dos impulsos sensoriais, mas o perfil seria o mesmo para todas as pessoas.

Entre os idealistas tanto o arbusto quanto o perfil são construções do intelecto, pois sentir e perceber são fenômenos que dependem da capacidade intelectual do sujeito em decompor um objeto em suas qualidades simples e recompor o objeto como um todo, dando-lhe organização e interpretação. Neste sentido tanto o arbusto quanto o perfil estratigráfico seriam apenas construções mentais, que em último caso teriam apenas uma existência ideal na mente de quem os observa.

Husserl tentou resolver a dicotomia entre a realidade empírica e a realidade apenas ideal propondo uma solução inovadora. $\mathrm{O}$ autor não nega a realidade e sua existência, mas considera que fatos e objetos não são apriorísticos, ou seja, não são totalmente independentes do sujeito. Para Husserl o ponto central da relação 
sujeito/objeto é a consciência. A consciência é sempre consciência de algo que se manifesta a uma consciência. É nesta relação que Husserl identifica a base da realidade. Neste sentido o importante é a vivencia, ou como define o autor, o processo pelo qual tudo que é informado pelos sentidos é mudado em uma experiência de consciência, em um fenômeno que consiste em estar consciente de algo (Cobra 2005). A fenomenologia de Husserl busca revelar o mundo a partir da experiência e não a partir do que acreditamos que a experiência seja.

Dentro deste processo de estar consciente de algo, não devemos nos preocupar se os objetos ideais correspondem ou não a objetos que são externos à nossa mente. Objetos, imagens, fantasias, atos, pensamentos, memórias, sentimentos, constituem nossas experiências de consciência. $O$ interesse não é o mundo que existe, mas o modo como o conhecimento do mundo se dá e tem lugar para cada um de nós. Experimentar algo implica estar consciente de algo. Neste sentido Husserl chama de fenômeno "tudo aquilo que é vivência, na unidade de vivência de um eu: fenomenologia é assim descrição de todos os fenômenos ou a significação de todas as nossas realidades: materiais, naturais, ideais, culturais". O objetivo de Husserl não é negar a existência de um mundo material ou idealizar um mundo de sonhos, mas compreender como o conhecimento do mundo acontece através das intencionalidades. No mundo em que vivemos não existe algo totalmente objetivo, reflexo puro da realidade tanto quanto não existe uma subjetividade que crie ou se imponha absolutamente ao mundo. O que efetivamente existe são os múltiplos aspectos da interação dessas duas dimensões na consciência.

A consciência segundo a fenomenologia é qualitativa, subjetiva, única, contínua estruturada e intencional. É qualitativa, pois toda a experiência tem certo sentimento qualitativo associado, assim ver uma árvore difere de sentir um perfume. Ela é subjetiva, pois a consciência só existe quando ela é experimentada por um organismo e neste sentido ela também é única já que não podemos saber exatamente o que se passa na mente dos outros organismos somente no nosso, somos inábeis em saber exatamente como outro organismo experimenta um objeto. Fenômenos no mundo objetivo são sentidos e percebidos de diferentes pontos de vista por diferentes organismos, ao passo que a consciência só é acessível do ponto de vista de cada organismo, ou seja, do sujeito que o experimenta. Consciência tem unidade na medida em que não podemos estar cientes de duas cenas incongruentes ao mesmo tempo. A consciência é contínua por experimentarmos continuamente e é estruturada, pois possui senso de familiaridade. Por fim ela é intencional, pois toda consciência é consciência de alguma coisa.

Ao considerar o papel da consciência Sartre vai além de Husserl ao propor que o Ego não estaria na consciência, mas fora, no mundo (Satre 1994). A intencionalidade seria assim o caráter fundamental da consciência e é por isso que a consciência transcende em si mesma e encontra sua unidade no objeto do qual é consciência. Desta maneira o objeto não se encerra em si, ele transcende à consciência que o apreende.

Segundo Chauí (1995), é através da percepção que nossa consciência relaciona-se com o mundo exterior. Percepção é vivencia, é o modo de a consciência relacionar-se com as coisas no mundo. Percepção é a forma como através dos sentidos as coisas do mundo natural e humano chegam a nossa consciência. Para poder conhecer e entender algo, a consciência ativa conceitos mentais que dão forma ao que é percebido, intermediando assim a relação sujeito/objeto. Perceber é traduzir um objeto de percepção em um julgamento de percepção, é estabelecer uma interpretação que tem lugar entre a consciência e o mundo percebido (Santella 1983). É a percepção que determina a forma com que os indivíduos vêem, interpretam e interferem em seu mundo (Rocha 2002/ 2003), a percepção determina nossa visão de mundo, sendo assim podemos dizer que há tantos mundos quantas forem as percepções, pois cada um vê seu entorno ou mais além a partir de suas experiências individuais.

Mas a percepção não é a única forma de vivenciar o mundo. Imaginar, pensar, lembrar, sonhar são também formas de experimentar o 
mundo. A diferença entre a experiência perceptiva e outras experiências como pensar e imaginar, sonhar, lembrar é que a experiência perceptiva tem um componente sensorial e outro conceitual, enquanto, pensar, imaginar, sonhar e relembrar são experiências apenas conceituais. Somente o aspecto conceitual da percepção fica disponível para outros atos conscientes, como lembrar, imaginar, pensar. A porção sensorial do ato de experimentar somente existe durante $o$ ato de perceber. Segundo Jacobs (2006), não podemos lembrar, imaginar e pensar aspectos da percepção que não foram conceitualizados no ato de perceber.

Para a fenomenologia não existe diferença entre percepção e sensação. Ambas são a mesma coisa. Sensações não são propriedades intrínsecas dos objetos sentidos, mas propriedades da atividade neurológica que são causadas por estímulos físicos que afetam nossos sentidos. Enquanto nossa informação sensorial é aproximada nossa percepção é mutável. Se sempre observássemos os objetos como eles são seria impossível explicar a mudança entre duas diferentes percepções, desde que os objetos não mudam, mas nossa percepção sim. Tomemos como exemplo as Figuras 1 e 2.

A primeira impressão que temos é de que se trata de um vaso e de um coelho. Mas observemos mais atentamente e a mágica acontece, temos agora um par de rostos e um pato. A mudança ocorre porque mudamos os conceitos que tomam parte de nossa percepção.

Fig. 1

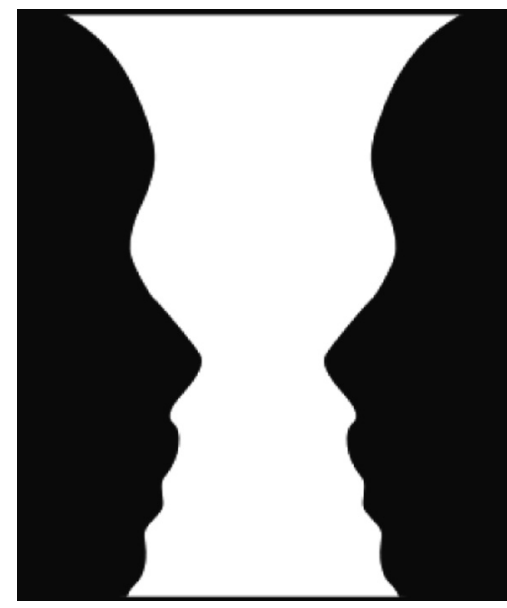

Fig. 2

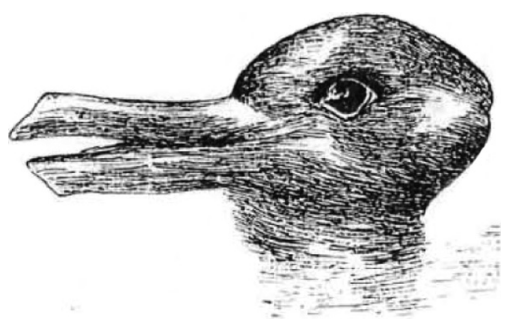

Sendo o estímulo constante, nossa experiência muda como resultado dos diferentes conceitos mentais utilizados para organizar o estímulo.

Ao mesmo tempo nunca temos sensações separadas de cada qualidade, nós não experimentamos sensações pontuais (Heidegger 1964). Sentimos e percebemos formas, isto é, totalidades estruturadas dotadas de sentido ou de significação. A idéia de unidade da percepção foi concebida pela primeira vez por Kant. Para ele os elementos mentais que tomam parte na percepção são organizados de forma que tenham algum sentido, e não por meio de processos de associação, como defendem os empiristas. Durante o processo de percepção, a mente cria uma experiência completa a partir da organização ativa dos elementos, de modo que se forme uma experiência coerente. Isto explica porque damos forma ao triangulo abaixo mesmo este não tendo seus lados definidos (Fig. 3).

Transpondo isso para nossa realidade podemos dizer que ter a sensação e a percepção de um perfil estratigráfico é sentir/perceber de uma só vez as cores que foram os segmentos, a disposição das camadas, sua textura, os elemen-

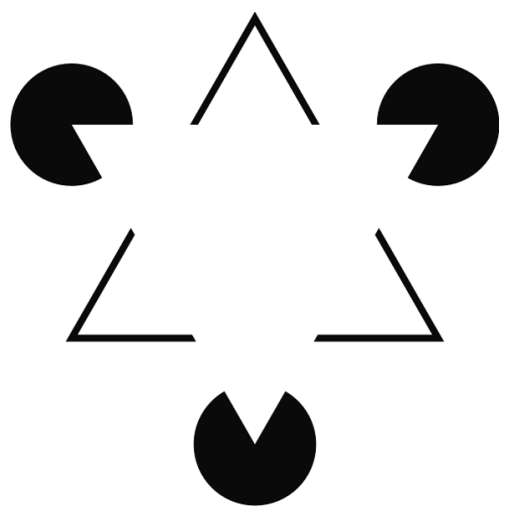


tos intrusivos. O perfil estratigráfico percebido não é um agrupamento de qualidades isoladas que enviam estímulos aos órgãos sensoriais como defendem os empiristas, muito menos um objeto indeterminado esperando que a mente informe aos sentidos que o objeto em questão é um perfil estratigráfico como supõem os idealistas. O perfil-percebido é apenas um perfil percebido não um mosaico de estímulos exteriores, nem uma idéia.

Se observássemos formas separadas veríamos as linhas abaixo como linhas de igual comprimento (Fig. 4). Na realidade elas têm o mesmo comprimento. A sensação de diferença surge do conjunto, da forma completa. Se retirássemos as extremidades das linhas as veríamos com o mesmo tamanho. O mesmo acontece com a figura ao lado onde à primeira vista o círculo central da figura da esquerda é menor que o círculo central da figura da direita (Fig. 5). No entanto, para nossa surpresa eles são do mesmo tamanho e diâmetro, podem medir. Na opinião dos empiristas isso é uma ilusão, um erro de percepção que não representa a realidade. Para a Gestalt, não há erro de percepção, porque percebemos o conjunto e o contexto da figura. O contexto influencia as partes e a forma da percepção. Se percebêssemos os círculos como círculos de tamanho igual, teríamos ai sim um erro de percepção, pois não estaríamos captando a gestalt perceptiva da figura.

Como ressalta Chauí (2000), "ver não é fazer geometria nem física. Não há ilusões na percepção; perceber é diferente de pensar e não uma forma inferior e deformada do pensamento" (Chauí 2000). Para a fenomenologia não existe ilusão, mas a correção de uma percepção por outra. Imaginemos, como sugere Chauí (2000), os versos de Mário de Andrade em que ele descreve um homem sob a neblina paulista. Este homem será percebido como negro à

Fig. 4

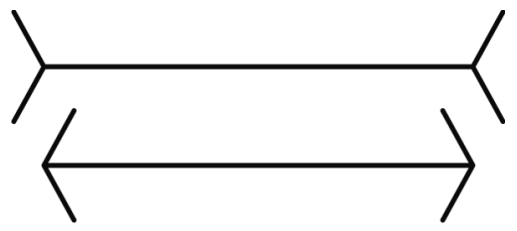

Fig. 5

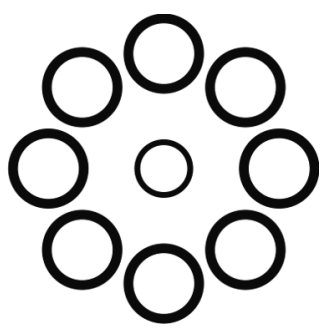

distância e como branco de perto. A correção da percepção se faz de acordo com a mudança do campo perceptivo. Conforme o campo perceptivo do objeto muda, nossa percepção também muda alterando a percepção inicial.

$\mathrm{Na}$ percepção visual das formas, as teorias da percepção advindas da Gestalt reconhecem quatro princípios básicos: tendência à estruturação ou seja, tendemos a organizar elementos que se encontram próximos uns dos outros ou que sejam semelhantes; segregação figura-fundo, que demostra que percebemos mais facilmente as figuras bem definidas e salientes que se inscrevem em fundos indefinidos e mal contornados; pregnância das formas, onde a qualidade das formas determina a facilidade com que percebemos figuras, assim percebemos mais facilmente as formas simples, regulares, simétricas e equilibradas; constância perceptiva, que se traduz na estabilidade da percepção, isto porque os seres humanos possuem uma resistência acentuada à mudança.

Embora captemos as formas completas, nunca podemos perceber de uma só vez um objeto. Não podemos ver de uma só vez todos os lados de um plano convexo por exemplo. Somente percebemos algumas de suas faces de cada vez. Mas mesmo observando apenas um dos lados da lesma sabemos que este objeto é um plano convexo. Isto acontece, pois nosso intelecto compreende uma idéia de uma só vez e por inteiro. A parcialidade da percepção é um atributo do fenômeno observado, dentro de um mundo que está sempre mudando seu caráter espaço-temporal (Tilley 2000). Nossa consciência transcende o perfil perspectivo da lesma a fim de apreendê-lo. A percepção assim nos fornece um objeto-consciência completo mesmo que somente parte do objeto seja intuitivamente dado. Segundo Husserl (1973) 
isto é possivel porque nossa consciência do objeto é sempre acompanhada pela consciência intencional do objeto, desta maneira nossa percepção forma intencionalmente os perfis ausentes. É por isso que conceitualizamos o todo da forma de um machado polido mesmo quando ele está parcialmente enterrado. A intencionalidade tensiona os perfis ausentes dando forma ao objeto.

Ao mesmo tempo às vezes vemos menos do que pensamos ver. Como demonstrou Dennett (1991), somos incapazes de distinguir cores na periferia de nosso campo visual. Somente quando um objeto se aproxima de nosso campo focal é que conseguimos perceber as cores.

Cores, cheiros, gosto, como eles ocorrem na percepção não são propriedades intrínsecas dos objetos que percebemos, mas construções de nossa mente (Huemer 2004; Maund 2003). Toda a informação sensorial é em si uma informação indireta sobre o objeto. A informação inerente na atividade sensorial não é idêntica às qualidades dos eventos e entidades, porque sensação é determinada não somente pela qualidade dos estímulos como também pela qualidade dos sentidos. Basta pensar que o que vemos é resultado da absorção de fótons com determinado comprimento de onda e que nossa visão não é capaz de capturar todos os comprimentos de onda que emanam do objeto. Se pensarmos que as capacidades de distinção sensorial variam de um indivíduo para outro e que todos os estímulos são transformados em atividade neural, podemos pensar que a informação inerente nas sensações são puramente simbólicas e subjetivas, ou seja, sensações são coleções potenciais de signos de entidades e eventos físicos (Jacobbs 2006). Desde que a habilidade de experimentar o mundo se traduz no uso das capacidades sensoriais e motoras podemos dizer que não há uma maneira certa ou correta de ver o mundo que nos cerca (Damasi 1994).

Percepção não é uma recepção passiva de informações. Percepção envolve movimento, basta pensar que vocês precisam movimentar os olhos ao longo das linhas deste texto para captar as informações. O que vemos, sentimos é formado e determinado pelo que fazemos e o que somos capazes de fazer. É por isso que temos dificuldade de imaginar situações que requerem movimentos que não são habituais para nós. Nossos órgãos sensoriais funcionam conjuntamente com nossa experiência cinestésica. Para Husserl (1962), a percepção não é independente da dimensão cinestésica, elas trabalham juntas para formar um significado completo para o objeto da percepção. Se imaginarmos que estamos diante de nosso perfil estratigráfico, a idéia do perfil está completa e formada, mesmo que alguns perfis estejam ausentes. Os perfis ausentes segundo estão ligados para um "se" intencional. Se eu me mover para a direita, se eu me mover para a esquerda, o novo perfil se torna acessível. Neste sentido percepção pressupõe movimento e para entender a percepção precisamos entender a própria intencionalidade de nosso corpo. A percepção depende das habilidades sensomotoras do observador. Para Noe (2004), percepção não é algo que acontece em nós ou para nós, mas algo que nós fazemos.

É por isso que Husserl dava ao corpo o estatuto de ponto zero de referência, pois é em referência a ele que o mundo consciente se organiza. Na sua relação com o mundo o corpo não se distancia das coisas a que está exposto, mas se vê em unidade com elas. O corpo está nas coisas que sente, vê, escuta, cheira. Desta primeira exposição, que tem uma intencionalidade natural, podem decorrer intencionalidades volitivas. Merleau-Ponty (1962) argúi que o corpo humano fornece o ponto fundamental de mediação entre o pensamento e o mundo na medida em que ele representa um meio de perceber e entender o mundo.

Mas nosso corpo é um organismo limitado. Não podemos voar, não podemos andar debaixo d'água, não conseguimos ver as ondas infravermelhas, ou seja, nosso corpo prescreve os tipos de experiência perceptivas e os processos cognitivos que são disponíveis a ele. A forma geral do corpo influencia diretamente em como ele vai realizar as ações comportamentais e em como ele irá perceber o mundo. Assim, um organismo com olhos irá experimentar o mundo de uma maneira diferente de um organismo desprovido de visão, um organismo 
sem pernas irá perceber e experimentar o mundo de maneira diferente do que um organismo com pernas.

Segundo Tilley (2000) o corpo em relação à experiência de mundo tem seis diferentes dimensões: acima, abaixo, à frente, atrás, à direita e à esquerda. Embora cada uma destas dimensões relate ao corpo elas o transcendem conectando-o com o mundo. Tais dimensões não são estáticas, mudam a cada momento, mudando também nossa relação com o mundo. Todas estas dimensões corporais mudam constantemente de acordo com o movimento do corpo, sendo assim coisas que estavam atrás passam a estar à frente, coisas que estavam à direita passam a estar à esquerda.

Em muitas culturas algumas dimensões corporais possuem significância metafórica, social e moral. Sendo assim, para cima pode ser associado com felicidade, para baixo com tristeza, à direita com operações legais, estar à esquerda pode significar o lado do mal, das operações ilícitas, o lado geralmente nefasto nas religiões (Van Der Kroef 1954). Devido ao fato de andarmos eretos nossos movimentos envolvem a mudança e a manutenção da orientação acima/abaixo. Se imaginarmos um ser esférico, vivendo em uma atmosfera sem gravidade, qual seria sua noção de acima e embaixo? E de que maneira poderia este ser associar acima com felicidade e abaixo com depressão? Será que ele descreveria a felicidade de maneira similar a que a maioria dos seres humanos descreve? Kaschak e Glenberg (2000) têm demonstrado que os seres humanos têm dificuldade em entender sentenças que descrevem ações para as quais o corpo humano não é propenso (Cowart 2005).

Nós ordenamos lugares e significados através de nosso corpo, através da articulação destas dimensões (Casey 1993). O mundo que existe é um mundo que existe para um sujeito e é continuamente definido e redefinido para o sujeito. Devido ao fato de a percepção ser mediada pelo corpo há um elemento corporal fundamental em nossa experiência de mundo. O corpo está continuamente improvisando sua relação com o mundo, dado o fato de ele não ser um mecanismo fechado, mas está constante- mente aberto ao mundo conforme ele se move. A maneira pela qual sentimos o mundo permanece incompleta e ambígua porque sempre experimentamos coisas a partir de um certo ponto de vista particular ou de uma relação particular (Tilley 2000). Conforme um organismo vai apreendendo a controlar seus próprios movimentos e suas performances ele vai desenvolvendo um entendimento de suas habilidades perceptivas básicas. Thilen e Smith (1994) chegam a acreditar que a linguagem e os processos cognitivos mais avançados não ocorrem sem a prática inicial das atividades motoras. Os autores acreditam que o desenvolvimento das práticas motoras, principalmente na infância, gera uma mudança na espacialidade e no comportamento dos organismos a partir da experimentação de diferentes categorias. Após certo número de experiências com eventos perceptivos específicos as crianças reconhecem que as soluções de ações orientadas são generalizantes. É desta maneira que elas associam estruturas de força particular com eventos específicos no mundo por exemplo. Para efetuar alguns comportamentos no tempo e no espaço a criança precisa aprender a categorizar situações e pensar nas soluções adequadas para cada situação. Lakoff and Johnson (1999) acreditam que existem conceitos básicos que derivam originalmente da maneira que nosso corpo interage com o meio. Tais conceitos seriam os gatinhos pelos quais as emoções básicas e as primeiras formas seriam percebidas e captadas.

Mas a maneira como os indivíduos experimentam e percebem o mundo não é condicionada apenas pela qualidade dos estímulos, pela forma do corpo e, por conseguinte, da recepção dos estímulos, ou da maneira como estruturamos as formas visualmente, ela é influenciada também pelo contexto histórico e cultural dos indivíduos. Para Jacobs (2006) influência cultural deve ser vista como a variação entre grupos culturais que se processa a partir de uma variação individual. Para influenciar a percepção, a cultura precisa transformar os conceitos mentais que são utilizados na percepção. Segundo o autor a cultura influencia a experiência se e somente se um indivíduo transforma seu tipo cognitivo interpretando 
expressões materiais que são interpretações individuais de tipos cognitivos. Ao mesmo tempo, a experiência e percepção influenciam a cultura se e somente se um indivíduo interpreta seu tipo cognitivo dentro de uma expressão pública que por sua vez é interpretada e conduz a transformação de tipos cognitivos por outros indivíduos. Estas transformações em curso resultam no ajuste dos conceitos mentais dos membros de uma dada cultura. Desde que conceitos mentais são utilizados na percepção, o ajuste dos conceitos mentais também influencia a percepção.

A cultura influencia a percepção porque sujeitos encontram e interpretam expressões públicas que são entidades naturais e eventos que contêm expressões individuais que conduzem à alteração dos conceitos mentais dos sujeitos. A expressão pública é o veículo para que a cultura influencie a percepção. Sem a expressão pública nenhuma informação pode ser transmitida, já que é impossível termos acesso direto à mente de cada pessoa. A expressão pública é produzida por um sujeito e encontrada e interpretada por outro sujeito como sendo uma interpretação pública. Uma das formas básicas de expressão pública é a linguagem. Para a fenomenologia, a função das palavras não é nomear tudo que vemos ou ouvimos, mas salientar os padrões recorrentes em nossa experiência. Uma palavra descreve não uma única experiência, mas um grupo de experiências. A palavra usada, por exemplo, para ponta de flecha descreve todos os vários dados dos sentidos que consultamos normalmente quando vemos ou relatamos o objeto.

Experiências passadas que não são diretamente experimentadas podem também influenciar na percepção. Em primeiro lugar elas modulam o mecanismo de avaliação emocional e em segundo lugar criam ou modulam nossos conceitos mentais (Jacobs 2006). Sem conceitos mentais os estímulos que resultam na percepção não seriam organizados. A experiência seria caótica sem percepção e sem emoção. Diferenças na ativação de conceitos mentais resultam em diferenças na qualidade da experimentação, como vimos nas
Figuras 1 e 2. É por isso que os índios não viram as primeiras caravelas no horizonte e é por isso que algumas características acabam nos escapando quando estamos analisando um perfil estratigráfico.

Se um estímulo particular leva à ativação de circuitos neurais codificando um conceito específico, todos os tipos de conceitos mentais relacionados a este conceito são também ativados resultando na associação de memórias, conhecimento e sentimentos. Mesmo conceitos mentais que à primeira vista não se referem à situação percebida podem ser ativados. Imaginemos, por exemplo, que recorrentemente analisamos os perfis que experimentamos com o auxílio de uma tabela de Munssell e em um determinado dia a esquecemos no quarto do hotel. A visão do perfil poderá ativar o conceito mental da tabela de Munssell mesmo que ela não esteja presente. Neste caso, temos a experiência conceitual, mas não perceptiva da tabela. Experimentar a tabela com ela nas mãos consiste em informação sensorial e conceitual, enquanto experimentar a tabela sem vê-la consiste em uma experiência apenas conceitual.

Segundo Howard (1987) a estrutura total dos conceitos mentais de cada indivíduo é única, porque conceitos mentais são formados e modelados de acordo com as experiências passadas e cada indivíduo tem a sua própria, pois experiência é individual. Os conceitos mentais e a maneira com que eles são criados e modulados são, assim, a fonte de variação na maneira pela qual indivíduos experimentam um dado fenômeno. Sem o emprego de conceitos na experiência perceptiva, o reconhecimento seria impossível mesmo se a informação sensorial fosse exatamente a mesma em duas ocasiões diferentes (Howard 1987).

Experimentamos o mundo porque vivemos neste mundo e estamos conectados a ele. Somos parte deste mundo e este mundo é parte de nós. Mente e corpo encontram o mundo a partir de um ponto de vista particular, em um contexto único, em um tempo específico e em um lugar singular. $\mathrm{O}$ corpo vivo, o corpo com 
uma mente é para todas as pessoas um meio particular de habitar o mundo, de estar presente no mundo, de sentir o mundo. Através do corpo aprendemos o que está acima e o que está abaixo, o que está à direita e o que está à esquerda, na frente ou atrás. Somos sujeito e objeto.

Nosso conhecimento do mundo, mesmo o cientifico, é feito sempre em primeira pessoa dentro de uma perspectiva individual. Mesmo o resultado científico mais exato pressupõe a relatividade subjetiva da evidência. A padronização dos métodos de pesquisa tem levado à falsa idéia de que a ciência é objetiva. $\mathrm{O}$ método pode ser objetivo, mas não podemos esquecer que sempre há o sujeito atuante na interpretação dos dados, na discussão das análises. $\mathrm{O}$ empirismo esquece o sujeito, mas devemos lembrar que o objeto percebido é sempre contextualizado não somente por seu entorno físico, mas também pelas ações particulares do observador, seus interesses pessoais, seu estado emocional além de suas habilidades e capacidades físicas. Não podemos nos livrar da subjetividade, uma vez que em toda experiência de consciência está envolvido o que é informado pelos sentidos e também o modo como a mente enfoca, trata aquilo que é informado. Quando tocamos nossa mão esquerda com a mão direita, somos tocados e ao mesmo tempo estamos tocando, somos objeto e sujeito. A subjetividade é física diria Tilley (2000).

A razão não está nas coisas, mas em nós. A razão é sempre razão subjetiva e não pode pretender conhecer a realidade tal como ela seria em si mesma nem pode pretender que exista uma razão objetiva governando as coisas. A razão conhece os objetos do conhecimento. Dentro deste universo, a percepção e as imagens que entram em nosso corpo são selecionadas pelo cérebro, ou seja, toda a percepção passa necessariamente pela nossa escolha, essas constituem para Bergson algo inexplicável, 'O que você tem a explicar, portanto, não é como a percepção nasce, mas como ela se limita, já ela seria, de direito, a imagem do todo, e ela se reduz, de fato, àquilo que interessa a você.” (Bergson1999).

\section{Ato III: $\mathrm{O}$ mundo real é o mundo percebido}

Nosso corpo, nossos sentidos, os conceitos mentais que temos estocado, os estímulos externos, o movimento, o contexto, a cultura, nossas intenções, tudo influencia nossa percepção do mundo, tudo influencia e é influenciado por nossa vivência e por nossas experiências. Ao nos movimentarmos pelo mundo, criamos um modelo mental de como o mundo funciona. Ao mesmo tempo em que nos movimentamos conhecemos o mundo e desenvolvemos sentimentos em relação a ele. À medida que nos movimentamos, sentimos e percebemos o mundo, vamos formando novos conceitos mentais que por sua vez vão alterando nossa própria percepção do mundo.

Paisagem, palavra de uso quotidiano, que cada indivíduo utiliza a seu modo, tem suas origens no Renascimento italiano e holandês. A paisagem era um meio particular de ver, uma técnica linear de perspectiva desenvolvida na pintura que tinha como objetivo criar imagens realistas da natureza. $\mathrm{Na}$ arte ocidental as paisagens são retratadas como se fossem vistas a partir de uma janela emoldurada. A ilusão associada com esse olhar cria uma moldura perceptiva.

O termo paisagem surge no Renascimento para nomear um novo tipo de relação entre o homem e o mundo que o cerca. É no relato de Petrarca em 1336 que Besse (2006) vê o nascimento de um novo olhar que irá se configurar como Paisagem. Ao subir o Monte Ventoux na França, Petrarca diz: Hoje comovido pelo simples desejo de ver um lugar reputado pela sua altura, subi o monte, o mais alto da região, denominado não sem razão Ventoux." (Besse 2006). Muito das definições estéticas desenvolvidas por Petrarca e ancoradas na filosofia aristotélica marcaram o olhar da arte paisagística renascentista. É neste sentido que a subida ao Ventoux marca uma data. A palavra paisagem se tornou corrente nos séculos XV, XVI e XVII, para se referir a pinturas. Segundo Poester (1995), o termo paisagem remonta ao francês paysage e ao flamengo landschamps que significam terra e teria sido utilizado pela primeira vez em 1493 por Jean de Molinet para 
designar uma pintura. Neves (2008) sugere outra etimologia ligada ao desenvolvimento da palavra inglesa landscape, que teria se originado do holandês landschaap que significa jurisdição ou área conquistada. Ambas têm parentesco com o alemão Landschaft que é o termo que nomeia uma cena que compreende uma cidade e seu entorno rural. Ainda segundo Neves em 1606, o pintor Karel van Mander, citando o pintor holandês Coninxloo diz "soo weet ick dier tyt geen beter landtschap-maker" (eu não conheço um melhor fazedor de paisagens desta época). Aqui a palavra landtshap é utilizada no lugar de natureza.

A idéia da paisagem, ou da pintura, como substituto da natureza se centra na premissa de que a imagem é o duplo do real que estava em voga durante o Renascimento. Sendo assim os pintores renascentistas viam na imagem a possibilidade de capturar a realidade. Esta forma de pensar e retratar o mundo em muito influenciou a concepção de paisagem que temos hoje em dia. De Platão a Satre a idéia de imagem como cópia do real se perpetuou na filosofia ocidental. Este é um olhar que vê o mundo de maneira desencarnada, se situa fora, é apenas expectador, vê a paisagem como um cenário, como em Hubert Von Eyck, Altdorfer e da Vinci. Durante o século XVIII, o homem sai de cena para dar lugar à paisagem como tema central. Alteram-se as relações figura e fundo e a paisagem passa a determinar campos de visão que se combinam em benefício da realidade da representação. Desenvolvem-se valores plásticos de expressão individual e a paisagem se torna algo mais íntimo como em Kandinsky. Mas mesmo a pretensa realidade da pintura paisagística holandesa se fia no empirismo com suas cores, texturas e sombras para retratar o real (Vieira 2006).

Segundo Cosgrove (1984) esta idéia de paisagem se tornou inseparavelmente associada às visões ocidentais e pós-iluministas do mundo, principalmente aquelas que viam na terra uma mercadoria alienável. Dentro da tradição de apreciação de arte ocidental e da criação de paisagens desenhadas, o visual sempre foi privilegiado. A própria arqueologia adotou o visual como mais relevante dentro da prática da arqueologia de paisagem convencional. Eu particularmente acredito que para que possamos realmente ver a paisagem precisamos atravessar a janela, precisamos romper o quadro com sua moldura, precisamos estar do outro lado e vivenciar o ambiente, precisamos entrar no espelho e tomar chá com o chapeleiro.

Cosgrove (1984) classifica a paisagem como um meio pictórico e cultural de estruturar, representar e simbolizar o entorno. Já Tilley (2006) pensa paisagem como uma imagem que é criada e lida de maneira verbal e não verbal. Ou seja, em ambos os casos a paisagem não é uma localidade, um território ou um espaço, mas uma representação subjetiva. A paisagem não é o mundo, mas sua representação.

Farina (2004) tem proposto uma conceituação de paisagem sob o ponto de vista da cognição. Segundo o autor três tipos de paisagem podem ser definidas: paisagem neutra, paisagem individual, paisagem observada. $\mathrm{O}$ que une cada tipo de paisagem é a maneira com que sinais e signos são interpretados. A paisagem neutra é o conjunto de estruturas e processos que os organismos não percebem distintivamente. Desta maneira a paisagem neutra é aquela não decodificada, ou seja, toda aquela paisagem fora da percepção do organismo. Já a paisagem individual é a percepção do entorno como determinado pelo aparelho sensorial. Por fim a paisagem observada ou percebida é a percepção humana do entorno. Na paisagem percebida os fatores culturais guiam e determinam a percepção. Neste sentido a cultura permite que o observador penetre mais profundamente decodificando e re-significando a paisagem. A proporção de cada categoria iria variar de acordo com a familiaridade que cada organismo tem de reconhecer o entorno. $\mathrm{O}$ problema com a classificação de Farina está no fato de o autor criar uma distinção entre sensação e percepção que como vimos acima não se justifica, já que sensação e percepção são a mesma coisa.

Neste sentido acho interessante a idéia de Jacobs (2006) que coloca a idéia de paisagens mentais ou paisagens experimentadas. A paisagem mental seriam construções individuais e subjetivas formadas a partir de um 
estímulo da paisagem física que é processado por mecanismos corticais e sub-corticais de avaliação e conceitos mentais. As qualidades da paisagem mental dependeriam da qualidade dos estímulos sensoriais, da qualidade do sistema sensorial e dos conceitos mentais que estão associados a um meio dinâmico constituído conscientemente em um dado momento. As propriedades do mecanismo de avaliação são influenciadas pela herança genética e pelas experiências passadas. As propriedades dos conceitos mentais são influenciadas pelas experiências passadas e pela expressão pública (Bourassa 1991). Paisagens mentais são construções simbólicas desde que as sensações resultantes dos estímulos físicos são puramente simbólicas e subjetivas em relação às propriedades do estímulo físico.

Tuan (1983) foi um dos primeiros a analisar o espaço sob o ponto de vista da percepção fenomenológica. Para o autor a percepção é tanto a resposta dos estímulos sensoriais externos quanto a atividade intencional da consciência que registra certos fenômenos enquanto ignora outros. Muito do que nós percebemos está envolto em fenômenos que nos interessam do ponto de vista emocional, prático, do ponto de vista da sobrevivência, ou do desejo de obter alguma satisfação, seja ela qual for.

Para Merleau-Ponty, o espaço não é o meio onde se dispõem as coisas, mas o meio pelo qual a posição das coisas se torna possível. $\mathrm{O}$ homem como ser ativo no mundo organiza e cria espaços de acordo com sua percepção do meio. O entendimento do espaço deve assim ser elaborado a partir da percepção, entendida como conhecimento intersubjetivo. Esta intersubjetividade refere-se ao encontro de invariantes situadas nas diversas formas de percepção do espaço, pela análise dos discursos sobre o mesmo, de forma a chegar a um discurso da essência. Percepção espacial busca entender como os homens se apropriam do espaço por eles vivenciado, como se dá sua consciência em relação ao meio que os encerra, como percebem e como reagem frente às condições e aos elementos da natureza ambiente, e como este processo se reflete na ação sobre o espaço. Assim, a busca seria por uma valorização subjetiva do território, em que as idiossincrasias individuais, e não coletivas, são valorizadas na avaliação. A paisagem aí passa a ser entendida como algo que contemple a percepção e a ação de atores subjetivos no meio que os contém (Tuan 1983; Maciel 2001).

Paisagem é uma conversa que o homem estabelece com mundo externo. Nessa conversa o homem percebe o mundo em constante construção, onde a dialética das imagens passam como se fossem flashbacks. Quando o homem toma contato com a paisagem este retira dela seus significados e significantes através do seu olhar, das suas sensações.

Não existem paisagens que não sejam mediadas pelo entendimento que o observador tem do seu mundo. Paisagens não são aspectos inertes que estão esperando serem exploradas, como casas não são construídas apenas para abrigar pessoas. Elas são contextualizadas, sentidas, cheiradas, tocadas, utilizadas nos termos da identidade individual e do entendimento cognitivo.

Embora diferenças culturais, idade e sexo influenciem na preferência por certas paisagens, o grau de experiência, de vivência na paisagem é o fator preponderante para a preferência por certos lugares do que por outros. Já para Jacobs (2006), a preferência por certos tipos de paisagem é resultado de quatro diferentes processos: Predisposição Inata associada às Emoções Inatas; Predisposição Corporal Inata; Aprendizado Inconsciente; Predisposição Consciente de Aprendizado. Tuan relaciona vínculo e falta de vínculo com os lugares com a percepção. Segundo ele para desenvolver sentimentos por um dado lugar é preciso viver nele, sofrer, crescer, amar, ou seja, vivenciar, perceber. Em geral quanto mais rápida for nossa passagem por um dado lugar menos será a experiência que teremos deste lugar, embora não se exclua a possibilidade de experiência intensa em curtos períodos de tempo. A intensidade das experiências determina os sentimentos em relação ao espaço. Segundo Proshansky e seu conceito de Identidade Local, não é possível que um mesmo indivíduo se aproprie de diversas paisagens ao 
mesmo tempo, pois o processo de apropriação envolve continuidade através de um determinado período de tempo.

Santos (2002) faz uma distinção entre espaço e paisagem. Para o autor paisagem e espaço não são sinônimos. "A paisagem seria um conjunto de formas que, num dado momento, exprime as heranças que representam as sucessivas relações localizadas entre homem e natureza. O espaço são as formas mais a vida que as anima” (2002: 103). Para ilustrar esta distinção, Santos recorre ao exemplo da Bomba de Nêutrons que tem a capacidade de aniquilar toda a vida humana em uma dada área, mas manter as construções. Se esta bomba fosse utilizada teríamos antes o espaço e após a explosão somente a paisagem.

Para Bachelard (1998, 2006), o espaço é o local povoado de afinidades, habitado por intimidades, desejos, medos e sonhos. O espaço para o autor é singular, situado e povoado por memórias, "um lugar de experiências colorido por emoções datadas”. O espaço de Bachelard, é um espaço que se singulariza na casa, na concha, na gaveta, na morada do afeto, é fonte da poésis artística que fundamenta a natureza enquanto paisagem (Pessanha 1988). Para Bachelard a imagem não é reflexo, mas criação. O espaço é o lugar da intimidade, o lugar onde desenvolvemos nossa relação imediata e direta com o mundo. Paisagem não é espaço e espaço não é paisagem. Para Jackson (1984), paisagem é um conjunto de espaços que são transformados pela ação humana. Cada lugar é único e especial, aninhado dentro de um topos em particular, ou "topografia". Para os gregos antigos, topos se refere a um lugar tangivel que imediatamente traz à mente uma série de associações. Lugares, como as coisas, evocam uma riqueza de imagens e idéias. Sempre nos encontramos indissoluvelmente apanhados e vinculados a lugares. Nosso conhecimento e experiência do espaço é, portanto, mais ontológica, ou "vivida", que matemática ou cartesiana.

Um mesmo espaço pode ser concebido de maneira diferente por indivíduos performando atividades diferentes. Isto porque atividades direcionadas determinam quais características do meio são relevantes para o sucesso da atividade. Desta maneira um cortador de grama irá perceber um campo de futebol de modo diferente do que um jogador, assim como um juiz conceberá também de maneira totalmente diferente o espaço do campo de futebol.

Espaço e paisagem têm sido vistos de maneiras múltiplas e ambíguas dentro da arqueologia. Sua história pode ser remontada à década de 20 do século passado com Gustaf Kossinna, que em seu livro The Origns of the Germans, desenvolve a idéia de assentamento a fim de justificar a definição de províncias culturais que representariam a evolução do povo germânico. Mas o tema da paisagem só ganhou força realmente nos anos 60 e 70 tanto na Inglaterra como nos Estados Unidos.

O termo Arqueologia da Paisagem aparece pela primeira vez com a publicação de Aston e Rowley (1974). A obra, que é considerada pelos britânicos como um marco, propõe uma maior associação entre as práticas de campo e o tema da paisagem, isto porque acreditavam os autores que a prática que estavam realizando ia além do reconhecimento e registro de sítios, passando a abordar paisagens culturais extensas e cronologicamente complexas. O interesse nos megalíticos europeus e outros vestígios arquitetônicos monumentais em escala regional, que representavam tipos de pensamento e ação humana que eram negligenciados pelas aproximações tradicionais, abasteceram vigorosamente estudos de paisagens sociais e simbólicas.

Ao mesmo tempo nos Estados Unidos os arqueólogos processualistas também passaram a reconhecer que modificações antropogênicas da paisagem envolvem mais do que modificações físicas do ambiente, já que elas também envolvem padrões ligados às dimensões sociais e ideológicas (Deetz 1990: 2).

Esta fase inicial da arqueologia da paisagem era caracterizada pelo estudo de fenômenos de grande escala que transcendia a estrita fronteira de localidades e "o mais alto nível de mediação entre o natural e o cultural, contra qual todas as outras culturas materiais mediantes são projetadas" (Fleming 2006). Em suas abordagens mais convencionais, os processualistas 
levavam em consideração a estruturação física e paleo-econômica do meio com sua topografia, declividade, áreas de captação de recurso ressaltando tudo o que foi feito na e com a terra, deixando pouco espaço para se discutir como as pessoas se engajaram emocionalmente, subjetivamente e variavelmente com a terra. A ênfase continuava sobre os sítios ou na melhor das hipóteses sobre a relação entre os sítios. Raramente se tirava os olhos do chão para se considerar a complexidade do entorno. Parte desta preocupação paleo-econômica e paleoecológica se inspirou em muito nos trabalhos de Vita-Finzi (1972) e nos trabalhos em que alguns arqueólogos consideram a interação de variáveis naturais e culturais como condicionantes das mudanças estruturais nos padrões de assentamentos. Estes pesquisadores presumem que o estudo das interações entre tais componentes permite um entendimento mais compreensivo do funcionamento do sistema e seus padrões de mudança.

Em contraponto a arqueologia de paisagem pós-processual começou a partir da idéia de que escrevemos o passado no presente. A principal crítica de Thomas (1993: 26), por exemplo, era que na arqueologia de paisagem tradicional, as pessoas estavam largamente ausentes. Ao contrário do que pensa Aston (1985), o trabalho do arqueólogo da paisagem não é apenas levar em consideração e detalhar as forças que circundam os indivíduos como demografia, clima, estruturas de uso de solo, tecnologia, níveis de organização social, meio ambiente etc.. Segundo Fleming (2006) este tipo de análise ecológica sistêmica resulta em uma abordagem que transforma o status metafísico dos seres humanos em meros fantasmas dentro da estrutura. Para Bender (1998), devemos ir além das evidencias de campo, já que as evidências não proporcionam em si um entendimento direto. Por exemplo, mapear um sítio não deveria ser uma planificação banal ou o registro das estruturas existentes. Ao contrário, o visitador precisa colocar o passado em uma experiência fenomenológica de "estar presente", criando assim um mapa mais profundo e completo. "Estruturas, campos, clima, solos são todos colocados no lugar, na crença de que dando um conhecimento totalizado de todos os outros fatores ... a presença humana ausente, deverá emergir" (Thomas 1993). O autor não defendia o abandono de metodologias tradicionais de análise, mas ressaltava que havia outros modos de pensar a paisagem.

A arqueologia da paisagem sob o pósprocessualismo propõe a reconstrução de mapas cognitivos e áreas de paisagem verificadas diferencialmente de acordo com o contexto. Não se trata mais de uma questão de reconstruir sistemas de assentamento apenas sob conceitos estruturais e territoriais; é mais uma questão de reconstruir paisagens rituais ao enfatizar o sistema de atual significância simbólica representado por seus objetos arqueológicos (Neustupny 1998).

Pearson e Shanks expressaram sua aproximação com a paisagem pós-processual em seu trabalho sobre Esgair Fraith, uma fazenda galesa em ruínas. Segundo o autor não devemos e não podemos confinar o espaço ao passado e dizer, "era assim que eles eram antes" (Pearson \& Shanks 2001: 156). Para os autores o que difere as abordagens contemporâneas daquelas anteriormente formuladas é aquilo que são considerados os "incentivos" que agem ou estão embutidos nos grupos humanos. Nas abordagens pós-processualistas da paisagem, não é a necessidade de "dominar" e se adaptar ao meio que age estruturando as ações e comportamentos humanos. São aspectos culturais, que abarcam não somente as relações de sobrevivência, mas também os fenômenos de percepção e atribuição de significados aos lugares. Uma abordagem fenomenológica da paisagem altera os desafios propostos pela geometria cartesiana do espaço que estão tão enraizados na moderna representação do espaço. Para Bachelard uma casa que tem sido experimentada não pode ser considerada uma caixa inerte, pois espaços experimentados, vividos transcendem o espaço geométrico. Precisamos escapar da rigidez dos nossos hábitos mentais. Espaço, para Bachelard, não é primariamente um recipiente de objetos tridimensionais. Ao contrário, o espaço é a morada da consciência humana, sendo assim o 
problema que a fenomenologia coloca é estudar como o espaço e a paisagem acomodam a consciência, ou meia consciência que Bachalard chama de devaneio.

Revelar os significados da paisagem exige uma habilidade imaginativa de entrar no mundo dos outros de maneira autoconsciente. "As paixões, inconvenientemente, às vezes assustadoramente, poderosas, motivadoras da ação humana, entre elas as morais, patrióticas, religiosas, sexuais e políticas influenciam nosso comportamento diário, contudo parecemos intencionalmente ignorá-las ou negá-las" (Cosgrove 1998: 97).

Parafraseando Cosgrove, nossa arqueologia deixa escapar muito do significado contido na paisagem humana tendendo a reduzi-la a uma impressão impessoal de forças demográficas e econômicas. A natureza é dinâmica. Árvores crescem e dão um clima de mistério à antiga floresta, a água se move com força e sutileza, o vento circunda as campinas, o tempo, ah o tempo, o tempo muda. Para aqueles que conseguem sentir o pulsar do coração do cervo em corrida, que conseguem sentir o frescor da manhã, para aqueles que vêem estrelas no céu e se apaixonam, para estes meu caro Oberon, uma descrição estática da paisagem não funciona. Todos esses sentimentos e percepções que as pessoas têm diante da paisagem fazem parte dela em certo sentido.

Através de suas atividades diárias, de suas crenças, valores, de seus movimentos, de sua percepção, os indivíduos transformam seu espaço físico em um espaço significante. Sendo assim a paisagem não é apenas o mundo que vemos, ela é uma construção, uma composição. É na paisagem que as pessoas se significam e significam seu mundo.

Pedro Nava em seu Balão Cativo nos alerta que é impossivel restaurar o passado em seu estado de pureza. Basta que ele tenha existido para que a memória o corrompa com lembranças superpostas. Talvez esse entrelaçamento de espaço e memória seja o fator da nossa principal dificuldade em fornecer uma base objetiva ao problema do significado do espaço. Creio que este problema se estende também à arqueologia enquanto ciência. Porque então insistir em uma pretensa objetividade? Eu prefiro insistir na imaginação. Para mim a imaginação arqueológica é a junção da percepção visual do presente que se mescla e é influenciada pelas representações e narrativas sociais do passado. Como tem proposto Bender (1998), aos arqueólogos não é permitido um salto imaginativo que é tão necessário para entender como as populações pré-históricas poderiam ter conceitualizado sua relação com seu próprio espaço. Devemos tentar encontrar por trás das imagens que se apresentam as imagens que se ocultam. Se criamos nosso mundo a cada dia, porque não pensar em uma nova arqueologia, com métodos sim, com rigor sim, mas sem amarras. Acredito que devamos nos permitir mais imaginação e mais devaneios, não há como existir e transcender sem imaginar, mas isso é assunto para outra história.

\section{Ato Final}

Puck: Meu caro Oberon convido você a imaginar como propôs Russell (1921) que alguém defenda a idéia de que há cinco minutos atrás deus criou o mundo como o conhecemos hoje, incluindo nós mesmos, nossas memórias do passado, as provas geológicas e fósseis sobre a origem da vida, e até mesmo este artigo. Embora toda a ciência moderna contradiga esta idéia, não podemos afirmar categoricamente que esta suposição seja falsa. Sendo assim, como conclui Jacobs (2006), todas as crenças que temos são no fim fundadas em suposições que não podem ser provadas como verdade. Neste sentido, o critério para uma boa suposição não é sua veracidade, mas se ela trabalha bem.

Dito isso me despeço e "se nós sombras vós ofendemos, pensai nisso e tudo estará resolvido; ficaste aqui dormindo enquanto apareciam estas visões e este fraco e humilde tema, que nada mais contém que um sonho. Gentis espectadores, não o condeneis, se nos perdoardes nós nos emendaremos, é a palavra do honrado Puck.” 
PELLINI, J.R. A Conversation on Archaeology and Landscape with Robin the Good Guy. Revista do Museu de Arqueologia e Etnologia, São Paulo, 19: 21-37, 2009.

\begin{abstract}
What is Landscape? How is defined the relationship between Man and Nature? What are symbols and meanings behind the Landscape? Would the approaches be exclusively centered on the paleoenvironment reconstructions the most close of the reality? Are the James Pride's and William Blake's emotional landscape, the realistic landscape of Delacroix and Velázquez, the liberty and energy of Van Gogh and Bomberg, the memories and dreams of Dali, Chagall and Carel Weight less true than the environmental reconstructions proposed by the archaeological science? According to Henry Frederic Amiel, the Swiss essayist of the XVII ${ }^{\text {th }}$ century, what distinguishes the landscapes from one another is just the mind. I would say that not just the mind, but the perception that the individuals have of their world.
\end{abstract}

Keywords: Phenomenology - Perception - Archaeology - Landscape.

\title{
Referências bibliográficas
}

ASTON, M.; ROWLEY, T.

1974 Landscape Archaeology: an Introduction to Fieldwork Techniques on post-Roman Landscapes. Newton Abbot: David \& Charles.

BACHELARD, G.

1998 A Poética do Espaço. São Paulo: Editora Martins Fontes.

2006 A Poética do Devaneio. São Paulo: Editora Martins Fontes.

BENDER, B.

1998 Stonehenge: Making Space. Leamington Spa: Berg.

BERGSON, $\mathrm{H}$.

1999 Matéria e Memória. Trad. Paulo Neves. São Paulo: Editora Martins Fontes.

BOURASSA, S.

1991 The aesthetics of landscape. London, New York: Belhaven Press.

CASEY, S.

1997 The fate of place: a philosophical history. Berkeley, Los Angeles, London: University of California Press.

CHAUÍ, M.

1995 Espinosa: uma filosofia da liberdade. São Paulo: Editora Moderna.

2000 Convite à Filosofia. São Paulo. Ática

COBRA, R.

2005 Fenomenologia. Filotemas In: www.cobra.pages.nom.br
COSGROVE, D.

1998 Social Formation and Symbolic Landscape. Wisconsin: University of Wisconsin Press.

2004 A Geografia está em toda Parte: Cultura e Simbolismo nas Paisagens Humanas. In: Rosendahl, Z.; Correa, R.L. (Eds.) Paisagem, tempo e cultura. 2. ed. Rio de Janeiro, EdUERJ: 92-123.

COWART, M.

2005 Embodied Cognition. International Internet Encyclophedia of Psycology. http://www.iep.utm.edu/embodcog/

DAMASIO, A.

1994 Descartes' Error: Emotion, Reason, and the Human Brain. New York: Grosset/Putnam.

DEETZ, J.

1990 Landscapes as cultural statements. In: Kelso, W.M.; Most, R. (Eds.) Earth Patterns: Essays in Landscape Archaeology. Charlottesville and London, University Press of Virginia: 2-4.

DENNETT, D.

1988 Quining qualia. In: A. Marcel; Bisiach, E. (Eds.) Consciousnessin modern science. Oxford, Oxford University Press: 42-77.

GALLAGHER, S.; ZAHAVI, D.

2008 The Phenomenological Mind. An Introduction to Philosophy of Mind and Cognitive Science. New York: Routledge. 
FLEMING, A.

2006 Post-processual Landscape Archaeology: a Critique. Cambridge Archaeological Journal, 16 (3): 267-280.

HOWARD, R.

1987 Concepts and schemata. London: Cassell Educational.

JACKSON, J.

1984 Discovering the vernacular landscape. New Haven: Yale University Press.

JACOBS, M.

2006 The Production of Mindscapes. A Comprehensive Theory of Landscape Experience. Dissertation Wagenigen Univertsity.

LAKOFF, G.; JOHNSON, M.

1999 Philosophy In the Flesh: The Embodied Mind And Its Challenge To Western Thought. New York, NY: Basic Books.

KASCHAK, M.; GLENBERG, A.

2000 Constructing Meaning: the Role of Affordances and Grammatical Consturctions in Sentence Comprehension. Journal of Memory and Langauge, 43: 508-529.

KOSSINNA, G.

1911 Die Herkunft der Germanen. Zur Methode der Siedlungsarchäologie. Mannus-Bibliothek 6, Würzburg .

HEIDEGGER, M.

1964 The origin of the work of art. In: Hofstadter, A.; Kuhns, R. (Eds.) Philosophies of Art and Beauty. Chicago, Chicago University Press: 649-701.

HUEMER, M.

2004 Sense data. Stanford Encyclopedia of Philosophy. Visto 6-7, 2004, http://

HUSSERL, E. plato.stanford.edu/entries/sense-data/

1962 Ideas: general introduction to pure phenomenology. London: Collier MacMillan Publishers.

1970 The Crisis of European Sciences and Transcendental Phenomenology. An Introduction to Phenomenology. Trans. D. Carr. Evanston, IL: Northwestern University Press.

MAUND, B.

2003 Perception. Chesham: Acumen Publishing Limited.

MERLEAU-PONTY, M.

1962 Phenomenology of Perception. London: Routledge and Kegan Paul.

NEVES, J.

2008 Paisagem e Denúncia: A Paisagem Contemporânea além da Contemplação
Estética da Natureza. Dissertação de Mestrado. Faculdade de Belas Artes da Universidade Federal de Minas Gerais.

NOE, A.

2004 Action in Perception. Cambridge, MA: MIT Press.

PEARSON, M.; SHANKS, M.

2001 Theatre Archaeology. London: Routledge. PESSANHA, J.

1988 Bachelard e Monet: o olho e a mão. In: NOVAES, Adauto (org.). O olhar. São Paulo. Companhia das Letras. pp. 149-166.

NEUSTUPNY, E.

1998 Space in prehistoric Bohemia. Prague, Institute of Archqeology.

PEARSON, M.; SHANKS, M.

2001 Theatre Archaeology. London: Routledge.

POESTER, T.

1995 Entre Limites, uma pintura em trânsito, Dissertação de Mestrado-IA-UFRGS, Porto Alegre.

ROCHA, L.

2002/03 Fenomenologia, Semiótica e Geografia da Percepção: Alternativas para Analisar o Espaço Geográfico. Revista da Casa de Sobral, 4/5: 67-79.

RUSSELL, B.

1921 The analysis of mind. London: Allen \& Unwin. SANTOS, M.

1996 A Natureza do Espaço. São Paulo: HUCITEC. SARTRE, J.

2005 O ser e o nada: o ensaio de ontologia fenomenológica. Petrópolis: Vozes.

SANTAELLA, L.

1983 O que é semiótica? São Paulo: Editora Brasiliense.

SHAPIRO, L.

2007 The Embodied Cognition Programme. Phylosophy Compass, 2 (2): 338-346.

TILLEY, C.

1997 A Phenomenology of Landscape. Places, Paths and Monuments. Oxford: Berg.

2004 The Materiality of Stone. Explorations in Landscape Phenomenology. Oxford: Berg.

THOMAS, J.

1993 The politics of vision and the archaeologies of landscape. In: Bender, B. (Ed.)

Landscape: Politics and Perspectives. Providence (RI), Berg: 19-48.

TUAN, Y.

1983 Espaço e lugar: a perspectiva da experiência. Tradução de Livia de Oliveira. São Paulo: Difel. 
VAN DER KROEF, J.

1954 Dualism and symbolic antithesis in Indonesian society. American Anthropologist, 56: $847-862$.

Recebido para publicação em 15 de dezembro de 2009.
VIEIRA, D.

2006 Paisagem e Imaginário: Contribuições Teóricas para uma História Cultural do Olhar. Revista de História e Estudos Culturais, 3 (3): 1-14. 